\title{
Primary cesearean section in multigravidas
}

\section{Sonia Arogya Prakash*, Archana Vikram, Raja Gopal K., Poluri Seeta Lavanya}

\author{
Department of Obstetrics and Gynaecology, Yenepoya Medical College, Mangalore, Karnataka, India
}

Received: 24 August 2016

Accepted: 24 September 2016

*Correspondence:

Dr. Sonia Arogya Praakash,

E-mail: drsoniareddy@gmail.com

Copyright: (C) the author(s), publisher and licensee Medip Academy. This is an open-access article distributed under the terms of the Creative Commons Attribution Non-Commercial License, which permits unrestricted non-commercial use, distribution, and reproduction in any medium, provided the original work is properly cited.

\section{ABSTRACT}

Background: Cesarean section is one of the widely performed surgical procedures across the world. Cesarean section is associated with increased risk of maternal morbidity and mortality, despite remarkable improvements in the safety. The objective of the present study is to study the cesearean section in the context of various indications, parity, intraoperative complications, post-operative morbidity, and perinatal morbidity among multigravidae undergoing cesarean section for first time.

Methods: The present study was carried out at Yenepoya medical college hospital. All multigravidas who had delivered vaginally once or more and who underwent primary caesarean sections for the first time during time period of August 2015-May 2016 were included in study and various factors are analyzed.

Results: In our study most of primary cesearean sections were in second paras who constituted $50 \%$, followed by $4 />$ paras constituting $29.54 \%$, and it was observed that incidence in third paras was $20.45 \%$. $75 \%$ of the patients underwent emergency cesearean section and $25 \%$ had elective ceserean section. The most common indication for cesearean in our study was observed to be fetal distress accounting for $25 \%$ of the cases, 2nd most common being malpresentations $(19.31 \%)$, non-progress of labor constituting $11.36 \%$ of cases. Intra operative complications were noted in $6.81 \%$ of cases, most common complication being extension of uterine incision extension of uterine incision. Conclusions: Complications may occur in women who previously had a normal vaginal delivery requiring interventions in the form of caesarean section and is not uncommon. Though to a small extent, they are contributing to rise is total caesarean section rates seen. There are many cases where a caesarean becomes mandatory for her. The fact that a multipara who has had one or more vaginal deliveries should be regarded as an optimistic historical fact, not as diagnostic-criteria for spontaneous delivery of the pregnancy at hand. A parous woman needs good obstetric care to improve maternal and neonatal outcome and still keeping caesarean section to a lower rate.

Keywords: Caesarean section, Multiparous, Parous women

\section{INTRODUCTION}

Cesarean section is one of the most commonly performed surgical procedure in the world and it can be life-saving for the child, the mother, or both, in some cases. ${ }^{1}$ There is worldwide increase in caesarean section rates. ${ }^{2}$

The World Health Organization recommends that the cesarean section rate should not be higher than $10 \%$ to $15 \%$. The rapid increase in the rate of cesarean section in the recent years deserves serious concern. Many Studies conducted across India have shown an alarming increase in the rate of cesarean section deliveries. ${ }^{3,4}$ Cesarean section poses a greater risk of maternal morbidity, mortality and high cost of health care compared with vaginal deliveries, hence it is important to assess the several indications, maternal and fetal outcome associated with a caesarean delivery which was demonstrated in numerous studies. ${ }^{4}$ There are several indications of cesarean sections, chiefly severe major degree of placenta previa and severe pre eclampsia, fetal distress, bad obstetric history $(\mathrm{BOH})$ and difficult vaginal operative delivery. ${ }^{5}$

It is a common belief in many that if a mother delivers her child normally, all her successive deliveries will be normal, resulting in the neglecting of routine antenatal 
check up by multiparous women. It is therefore felt need to study the indications for cesarean section and outcome among women who have previously delivered vaginally. 6,7 The present study is undertaken with the objectives to know the indications of primary cesarean section in multigravidae, incidence according to parity, maternal and fetal outcome.

\section{METHODS}

The present study is carried out at Yenepoya medical college hospital. All multigravidas who had delivered vaginally once or more and who underwent primary caesarean sections for the first time during time period of August 2015 to May 2016 were included in the study.

\section{Inclusion criteria}

- Multigravidas

- Term pregnancy

- Singleton pregnancy

\section{Exclusion criteria}

- Primigravida

- Previous LSCS

- Gestational age $<37$ weeks

\section{RESULTS}

In our study most of primary cesearean sections were second paras who constituted $50 \%$, followed by $4 />$ paras constituting $29.54 \%$ and it was observed that incidence in third gravidas was $20.45 \%$.

Table 1: Distribution according to parity.

\begin{tabular}{|lll|}
\hline Gravidity & Number & Percentage \\
\hline 2 & 44 & $50 \%$ \\
\hline 3 & 18 & $20.45 \%$ \\
\hline$>/=4$ & 26 & $29.54 \%$ \\
\hline
\end{tabular}

Table 2: Type of cesearean section.

\begin{tabular}{|lll|}
\hline Type of CS & Number & Percentage \\
\hline Emergency & 66 & $75 \%$ \\
\hline Elective & 22 & $25 \%$ \\
\hline
\end{tabular}

In this study $75 \%$ of the patients underwent emergency cesearean section and $25 \%$ had elective ceserean section.

The most common indication for cesearean in our study was observed to be fetal distress accounting for $25 \%$ of the cases, 2nd most common being malpresentations (19.31\%), non-progress of labor constituting $11.36 \%$ of cases followed by medical disorders accounting for $6.81 \%$ of cases and APH and TWIN gestation constituting $5.68 \%$ each.
Table 3: Indications for cesearean section.

\begin{tabular}{|lll|}
\hline Indications & Number & Percentage \\
\hline Oligohydramnios & 3 & $3.4 \%$ \\
\hline Malpresentations & 17 & $19.31 \%$ \\
\hline APH & 6 & $6.81 \%$ \\
\hline CPD & 5 & $5.68 \%$ \\
\hline Medical disorders & 6 & $6.81 \%$ \\
\hline Fetal distress & 22 & $25 \%$ \\
\hline Non-reactive NST & 3 & $3.41 \%$ \\
\hline Non-progress & 10 & $11.36 \%$ \\
\hline Cord prolapsed & 4 & $4.54 \%$ \\
\hline Twins & 5 & $5.68 \%$ \\
\hline MSL & 2 & $2.27 \%$ \\
\hline Second stage arrest & 3 & $3.41 \%$ \\
\hline BOH & 1 & $1.13 \%$ \\
\hline Altered Doppler & 1 & $1.13 \%$ \\
\hline
\end{tabular}

Intra operative complications were noted in $6.81 \%$ of cases, most common complication being extension of uterine incision extension of uterine incision.

Table 4: Intraop complications.

\begin{tabular}{|llc|}
\hline Complication & Number & Percentage \\
\hline PPH & 2 & $2.27 \%$ \\
\hline $\begin{array}{l}\text { Extension of } \\
\text { uterine incision }\end{array}$ & 4 & $4.54 \%$ \\
\hline
\end{tabular}

Post-operative morbidity was observed in $10.22 \%$ of cases which includes febrile morbidity $(3.41 \%)$, wound infection $(2.27 \%)$, urinary tract infection $(2.27 \%)$, abdomen distension (1.13\%), and psychosis (1.13\%).

Table 5: Post op morbidity.

\begin{tabular}{|lcl|}
\hline Type & Number & Percentage \\
\hline Wound infection & 2 & $2.27 \%$ \\
\hline Febrile morbidity & 3 & $3.41 \%$ \\
\hline $\begin{array}{l}\text { Urinary tract } \\
\text { infection }\end{array}$ & 2 & $2.27 \%$ \\
\hline $\begin{array}{l}\text { Abdomen } \\
\text { distension }\end{array}$ & 1 & $1.13 \%$ \\
\hline Psychosis & 1 & $1.13 \%$ \\
\hline Total & 9 & $10.22 \%$ \\
\hline
\end{tabular}

Table 6: Perinatal morbidity.

\begin{tabular}{|llc|}
\hline Type & number & Percentage \\
\hline Low Apgar & 3 & $3.41 \%$ \\
\hline Sepsis and pyrexia & 2 & $2.27 \%$ \\
\hline $\begin{array}{l}\text { Meconium } \\
\text { aspiration }\end{array}$ & 2 & $2.27 \%$ \\
\hline Convulsions & 1 & $1.13 \%$ \\
\hline Respiratory distress & 2 & $2.27 \%$ \\
\hline
\end{tabular}


Perinatal morbidity was seen in $11.36 \%$ of babies with low Apgar in $3.41 \%$ of cases, sepsis in $2.27 \%$, meconium aspiration in $2.27 \%$, respiratory distress in $2.27 \%$, and convulsions noted in $1.13 \%$ babies.

\section{DISCUSSION}

In the present study, maximum number of women undergoing primary cesarean section were in second paras $44(50 \%)$, followed by $4 />$ paras constituting $29.54 \%$ and it was observed that incidence in third paras was $20.45 \%$. These were similar to a study by Desai et al, among the patients undergoing C-section, the number of Primipara patients were $30(34.88 \%)$, number of 2 nd parapatients were $20(23.26 \%)$, number of 3rd para patients were also $20(23.26 \%)$, number of 4 th para patients were $9(10.47 \%)$, number of 5 th para patients were $4(4.65 \%)$ and number of 6th para patients were just $3(3.49 \%)$. $^{9}$

In our study $75 \%$ of the patients underwent emergency cesearean section and $25 \%$ had elective ceserean section. This findings were in close proximity to a study done by Al Rowaily et al, where two-thirds (67\%) were emergency CSs, and one-third were elective CSs (33\%). ${ }^{10}$

The most common indication for cesearean in our study was observed to be fetal distress accounting for $25 \%$ of the cases, $2^{\text {nd }}$ most common being malpresentations (19.31\%), non-progress of labor constituting $11.36 \%$ of cases followed by medical disorders accounting for $6.81 \%$ of cases and APH and TWIN gestation constituting $5.68 \%$ each. Similar indications were found in a study done by Desai E et al Fetal distress was the most common indication having highest number of cases $22(25.58 \%)$, next most common being the APH whose cases were $19(22.09 \%)$, than the number of cases having CPD was 17 (19.77\%), number of patients having Abnormal presentations was $15(17.44 \%){ }^{9}$

Intra operative complications were noted in $6.81 \%$ of cases, most common complication being extension of uterine incision extension of uterine incision. Postoperative morbidity was observed in $10.22 \%$ of cases which includes febrile morbidity $(3.41 \%)$, wound infection $(2.27 \%)$, urinary tract infection $(2.27 \%)$, abdomen distension $(1.13 \%)$, psychosis $(1.13 \%)$. These findings were similar to study by Jyothi H Rao. ${ }^{11}$

Perinatal morbidity was seen in $11.36 \%$ of babies who required NICU admission, with low Apgar in $3.41 \%$ of cases, sepsis in $2.27 \%$, meconium aspiration in $2.27 \%$, respiratory distress in $2.27 \%$, and convulsions noted in $1.13 \%$ babies.

These findings were similar to study by Sethi et al. ${ }^{12}$ In this study 17 babies had perinatal morbidity, Birth asphyxia was seen in 4 babies, sepsis and pyrexia was observed among 4 babies, convulsions, MAS and RDS was seen in 3 babies each.

\section{CONCLUSION}

Complications may occur in women who previously had a normal vaginal delivery requiring interventions in the form of caesarean section and is not uncommon. Though to a small extent, they are contributing to rise is total caesarean section rates seen. There are many cases where a caesarean becomes mandatory for her. The fact that a multipara who has had one or more vaginal deliveries should be regarded as an optimistic historical fact, not as diagnostic-criteria for spontaneous delivery of the pregnancy at hand. A parous woman needs good obstetric care to improve maternal and neonatal outcome and still keeping caesarean section to a lower rate, and proper counseling of the patients in cases where cesearean section is mandatory.

\section{Funding: No funding sources}

Conflict of interest: None declared

Ethical approval: The study was approved by the Institutional Ethics Committee

\section{REFERENCES}

1. Khan R, Blum LS, Sultana M, Bilkis S, Koblinsky M. An examination of women experiencing obstetric complications requiring emergency care: perceptions and sociocultural consequences of caesarean sections in Bangladesh. J Health Popul Nutr. 2012;30(2):15971.

2. Lumbiganon $\mathrm{P}$, Laopaiboon M, Gulmezoglu AM, Souza JP, Taneepanichskul S, Ruyem P, et al. Method of delivery and pregnancy outcomes in Asia: the WHO global survey on maternal and perinatal health 2007-08. Lancet. 2010;375(9713):490-9.

3. World Health Organization. Indicators to monitor maternal health goals: report of a technical working group, Geneva, 8-12 November 1993. Geneva. WHO. 1944. pp. 44.

4. Singh G, Gupta ED. Rising Incidence of Caesarean Section in Rural Area In Haryana India: A Retrospective Analysis. The Internet Journal of Gynecology and Obstetrics. 2013;17(2).

5. Gregory KD, Jackson S, Korst L, Fridman M. Cesarean versus vaginal delivery: whose risks? Whose benefits? Am J Perinatol. 2012;29:7-18.

6. Hickl EJ. The safety of cesarean section. In: Popkin DR and Peddle LJ, Eds. Women's Health Today. London: Parthenon Publishers. 1994. pp. 65-70.

7. Mala V, Bhaskar Rao K. Cesarean deliveries Changing Trends. In: Arulkumaran S, Ratnam SS, Bhasker Rao K (Editors). The Management of Labour, 2nd Ed., Hyderabad, Orient Longman. 2005. pp. 351-63.

8. Basak S, Lahiri D. Dystocia in Eutocic multigravidae. J Obstet Gynec. 1975;25:502-7.

9. Desai E, Leuva H, Leuva B, Kanani M. A study of primary caesarean section in multipara. Int J Reprod Contracept Obstet Gynecol. 2013;2:320-4. 
10. Al Rowaily. Cesarean section in a high-parity community in Saudi Arabia: clinical indications and obstetric outcomes. BMC Pregnancy and Childbirth. 2014;14:92.

11. Rao JH, Rampure N. Study of Primary Caesarean Section in Multiparous Women. Journal of Evolution of Medical and Dental Sciences. 2013;2(24):4414-8.
12. Sethi P, Vijaylaxmi S, Shailaja G, Bodhare T, Devi S. A study of primary cesarean section in multigravidae. Perspectives in medical research 2014;2(2).

Cite this article as: Prakash SA, Vikram A, Raja Gopal K, Lavanya PS. Primary cesearean section in multigravidas. Int J Reprod Contracept Obstet Gynecol 2016;5:3849-52. 